\title{
低温度 $\mathrm{Ar}+\mathrm{O}_{2}$ ガス気流中での溶融アルミニウム の蒸発速度と凝縮粒子の性状
}

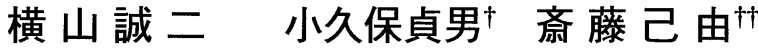 \\ 伊藤公允柿 川上正博
}

豊橋技術科学大学生産システム工学系

J. Japan Inst. Metals, Vol. 57, No. 3 (1993), pp. 282-288

\section{Evaporation Rate of Molten Aluminum in Low Temperature $\mathrm{Ar}+\mathrm{O}_{2}$ Gas Flow and Characteristics of Condensed Particles}

Seiji Yokoyama, Sadao Kokubo, Katsuyoshi Saito, Koin Ito and Masahiro Kawakami

Department of Production Systems Engineering, Toyohashi University of Technology, Toyohashi

\begin{abstract}
Molten aluminum was evaporated in a cold gas stream of $\mathrm{Ar}+\mathrm{O}_{2}$ mixture in order to investigate both the evaporation rate of the liquid metal and the characteristics of condensed particle in the reactive gas stream. Experiments were carried out under various oxygen partial pressures $\left(P_{\mathrm{O}_{2}}\right)$, temperatures and total gas flow rates using a levitation melting apparatus. The relations between the evaporation rate and $P_{\mathrm{O}_{2}}$ could be classified into three regions; i. e. low, medium and high $P_{\mathrm{O}_{2}}$ regions. The rate in each $P_{\mathrm{O}_{2}}$ region was discussed using a counter flux model of aluminum vapor and oxygen in the boundary layer around the levitated specimen.

The results obtained in each $P_{\mathrm{O}_{2}}$ region were summarized as follows:

(1) Low $P_{\mathrm{O}_{2}}$ region: As most oxygen reacted with aluminum particles after condensation of the aluminum vapor, the evaporation rate was almost the same as the one in the Ar gas stream irrespective of $P_{\mathrm{O}_{2}}$. The condensed particles were a mixture of aluminum and widely defined $\gamma-\mathrm{Al}_{2} \mathrm{O}_{3}$. The amount of the $\gamma-\mathrm{Al}_{2} \mathrm{O}_{3}$ increased with an increase of $P_{\mathrm{O}_{2}}$.

(2) Medium $P_{\mathrm{O}_{2}}$ region: As oxygen diffused beyond the site where the aluminum vapor nucleated, it reacted with the aluminum vapor. The boundary layer thickness for the aluminum vapor decreased with an increase of $P_{\mathrm{O}_{2}}$, so that the evaporation rate increased linearly. The condensed particles were almost widely defined $\gamma-\mathrm{Al}_{2} \mathrm{O}_{3}$. As a whole, it could be said that the mean particle diameter decreased with increasing $P_{\mathrm{O}_{2}}$ and total gas flow rate and with decreasing temperature.

(3) High $P_{\mathrm{O}_{2}}$ region: As oxygen diffused onto the levitated specimen surface, an oxide film covered on the specimen surface. Accordingly, the vaporization of aluminum ceased and no particle was obtained.
\end{abstract}

(Received October 16, 1992)

Keywords: aluminum, evaporation rate, levitation melting, argon + oxygen gas mixture, particle diameter distribution, $\gamma-\mathrm{Al}_{2} \mathrm{O}_{3}$, ultra fine particle

\section{I． 緒言}

超微粒子合成法の一つに減圧下の不活性ガス中で金属を蒸 発，凝縮させるガス中蒸発・凝縮法がある(1)。この方法に拈い ては，不活性ガスに酸素などの反応性ガスを添加することによ り酸化物などの化合物超微粒子まで合成されている. 従来のガ ス中蒸発法に関する研究は減圧下に执いてなされたものが多 く, 大気圧下での研究は少ない，そこで前報(2)では，大気圧下 での低温度不活性ガス気流中で溶融 $\mathrm{Al}$ を蒸発させる実験を行

$\dagger$ 豊橋技術科学大学大学院生, 現在 : 昭和アルミニウム(㹯)

† 豊橋技術科学大学大学院生

什 豊橋技術科学大学生産システム工学系, 現在名誉教授
い, 蒸発速度と凝縮粒子の大きさについて浮揚試料周辺の温度 分布と均質核生成理論を用いて検討した。その結果, 蒸発速 度, 平均粒子径㧊よび粒子径分布の分散は予測できることなど を明らかにした。

本研究では, ガス中蒸発法の基礎研究の一環として, 大気圧 下の反応性ガス気流中での溶融金属の蒸発速度と凝縮粒子性状 について調査，検討する．大気圧下での溶融金属の蒸発速度 は，金属蒸気と反応するガスを添加することによって増大する ことが知られているが，凝縮粒子については汪とんど検討され ていない(3)(4)。そこで前報と同じく溶融金属に $\mathrm{Al}$ を選び， $\mathrm{Ar}+\mathrm{O}_{2}$ 気流中でそれを蒸発させる実験を行い, 蒸発速度(凝 縮粒子に着目すれば粒子の生成速度) と凝縮粒子の両者につい て調査, 検討した。 


\section{II. 実験}

実験装置，供試材料と実験方法は前報に述べたものと大略同 じなので，以下に略記する。

実験に用いた装置の概略をFig. 1に示した，所定流量の $\operatorname{Ar}(99.9 \mathrm{~mol} \%)$ を反応管内に流しながら，浮揚溶解用 $\mathrm{Al}$ 試料 （純度 99.8 mass\%，質量 $3.500 \pm 0.005 \times 10^{-3} \mathrm{~kg}$ ）を石英台に 載せて溶解コイルの位置要で上げ浮揚溶解した。試料々約 20 $\mathrm{s}$ で溶解した後, $10 \mathrm{~s}$ 後の約 $1773 \mathrm{~K}$ で蒸発が目視で認めら れ，約 $1823 \mathrm{~K}$ で試料表面の酸化物粒子は除去された。蒸発が 目視で認められる時刻を時間の基準とした。酸素 (99.5 mol\%) を添加するとA $\mathrm{A}$ と酸素との反応熱により試料温度は上昇し た。 そこで, 実験温度よりる低い温度で所定流量の酸素を $\mathrm{Ar}$ ガスに添加し，高周波発振機の出力を調整して，試料を実験温 度に $\pm 10 \mathrm{~K} て ゙$ 保持した. 所定時間経過後, 酸素流入を止めて 加 $10 \mathrm{~s}$ 後炕電源を㽖り，試料を水冷鋳型に落下させ急冷採 取した。

蒸発質量は, 酸素流入停止後のAr 中での蒸発質量を考慮し $\tau$ ，実験前後の浮揚試科の質量差より算出した。凝縮粒子を TEM, SEM，粉末 X 線回折で観察，同定した。京た，画像解 析装置でその粒径(円相当径)を1000 2000個の範囲で測定し た.

実験条件をTable 1 と示した. Table 1 と示したガス流量は $293 \mathrm{~K}$ で測定したものである，発振機性能の制約から Ar 気流 中で試料を安定に保持できる温度範团は 1873 2323 K であっ たが，酸素を添加すると浮揚 $\mathrm{Al}$ 陚料は摇動し， $\mathrm{Ar}+\mathrm{O}_{2}$ 気流 中では約 $2023 \mathrm{~K}$ 以下の温度化試料を保持することは困難であ った。そこで実験は Table 1 に示す温度範团で行った。実験は 各Run no. に扣いて温度と全ガス流量を一定に保持して，酸 素分生 $P_{\mathrm{O}_{2}}\left(P_{\mathrm{O}_{2}}+P_{\mathrm{Ar}}=101.3 \mathrm{kPa}\right)$ 变完て行った，ただし酸素

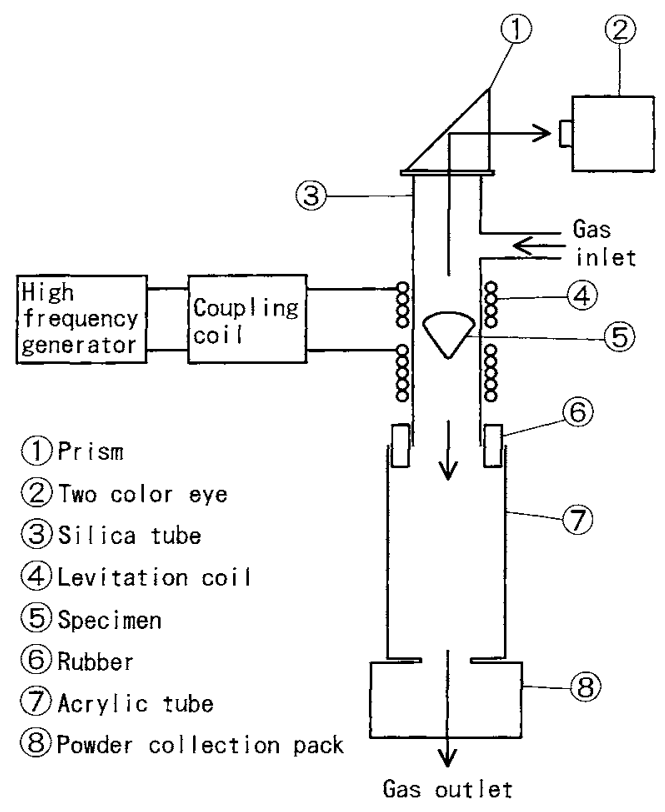

Fig. 1 Schematic diagram of the experimental apparatus.
Table 1 Experimental conditions. Total gas flow rate $\left(\mathrm{Ar}+\mathrm{O}_{2}\right)$ was measured at $293 \mathrm{~K}$.

\begin{tabular}{c|c|c|c}
\hline \hline $\begin{array}{c}\text { Run } \\
\text { no. }\end{array}$ & Temperature $/ \mathrm{K}$ & $\begin{array}{c}\text { Total gas flow } \\
\text { rate } / 10^{-5} \mathrm{~m}^{3} \cdot \mathrm{s}^{-1}\end{array}$ & $\begin{array}{c}\text { Oxygen partial } \\
\text { pressure, } P_{\mathrm{O}_{2}} / \mathrm{kPa}\end{array}$ \\
\hline 1 & 2073 & 8.3 & $0.0 \sim 3.5$ \\
2 & 2073 & 16.7 & $0.0 \sim 3.5$ \\
3 & 2073 & 25.0 & $0.0 \sim 3.5$ \\
\hline 4 & 2173 & 16.7 & $0.0 \sim 4.5$ \\
\hline 5 & 2273 & 8.3 & $0.0 \sim 4.5$ \\
6 & 2273 & 16.7 & $0.0 \sim 4.5$ \\
7 & 2273 & 25.0 & $0.0 \sim 4.5$ \\
\hline
\end{tabular}

を添加していない $\mathrm{Ar}$ 気流のみの実験に括ける酸素分圧を $P_{\mathrm{O}_{2}}$ $=0.0 \mathrm{kPa}$ とした. Run nos. 1 3 と Run nos. $5 \sim 7$ では, 温 度を一定にして蒸発速度に招よぼす全ガス流量の影響を調べ， Run no. 1 と no. 5, Run nos. 2, 4, 6 抢よび Run no. 3 と no. 7 では，全ガス流量を一定にして蒸発速度に扣よぼす温度の影響 を調查した。

\section{III. 実 験 結 果}

\section{1. 蒸発速度}

\section{（1）酸素分圧および温度の影響}

$\mathrm{Ar}+\mathrm{O}_{2}$ 気流中での蒸発質量の経時变化に扣よぼす酸素分圧 $P_{\mathrm{O}_{2}}$ の影響を Fig. 2 亿例示した。図の縦軸の值には, 蒸発質量 初期の浮揚 $\mathrm{Al}$ 試料の外形形状から算出した表面積で除した 単位面積当たりの蒸発質量值を用いた. $0 \leqq P_{\mathrm{O}_{2}} \leqq 2.7 \mathrm{kPa}$ の範 囲では蒸発質量は時間とともに直線的に増大した。これは前 報(2)で述へたたよに蒸発量が小さいので表面積はあまり変化し ていないことによる. $P_{\mathrm{O}_{2}}=3.2 \mathrm{kPa}$ で蒸発質量は初期に招い て直線的に増大した後，したいに蒸発速度は低下し，ある時間 経過後蒸発は汪とんど進行しなかった，蒸発質量が直線的増加 から曲線的増加に变化する時間で，浮揚試料の上部にまず酸化 物が喼められた，その酸化物は時間経過とと的膜状に成長 し，最終的には浮揚 $\mathrm{Al}$ 試料全表面を覆った．したがって浮揚 試料の自由表面積が時間とともに減少しているので，蒸癹質量

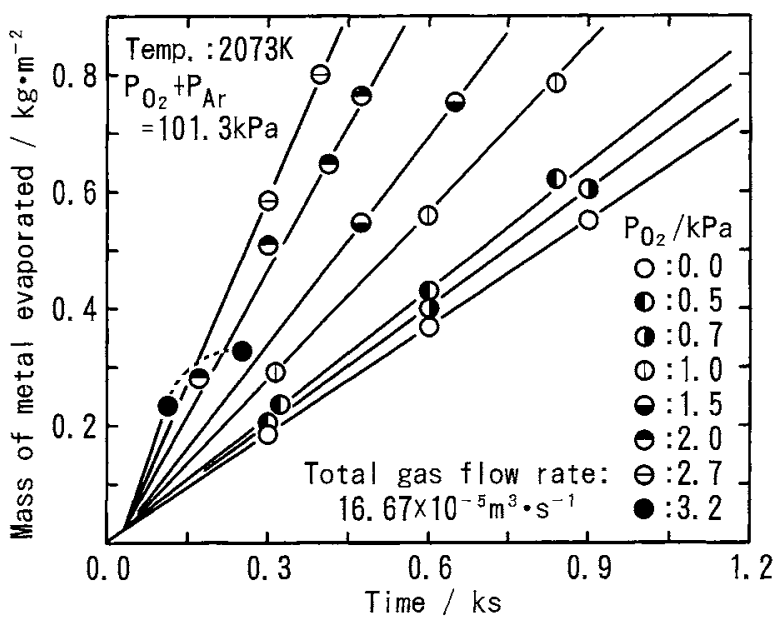

Fig. 2 Change in mass of metal evaporated with time. 


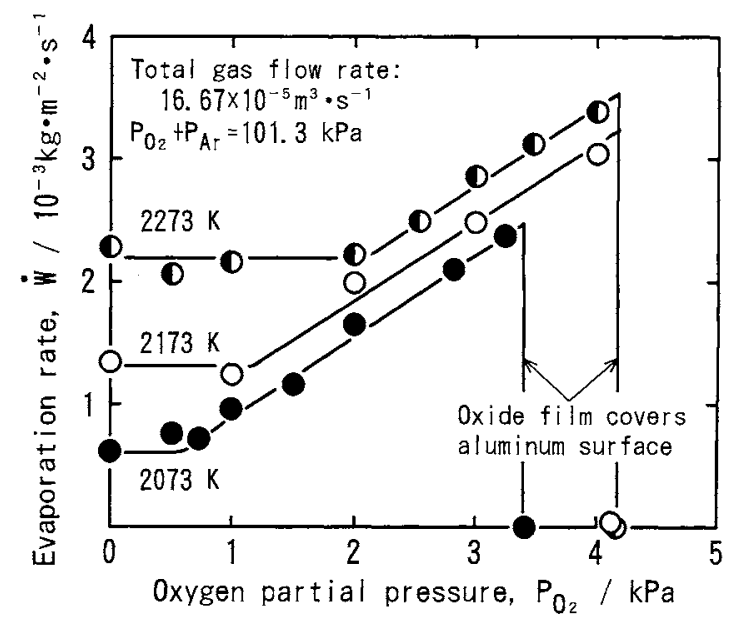

Fig. 3 Effect of $P_{\mathrm{O}_{2}}$ on the evaporation rate at each temperature.

が曲線的に增加したものと思われる. $P_{\mathrm{O}_{2}}>3.4 \mathrm{kPa}$ では酸素を 添加すると同時に酸化膜が生成し，蒸発減量の測定は困難であ った.

各温度に拈りる蒸発速度と酸素分圧の関係を Fig. 3 亿示し た.ここで蒸発速度はFig. 2 に例示した值線の傾さである。 各温度に扣いて, 蒸発速度之酸素分圧の関係は 3 つの領域,

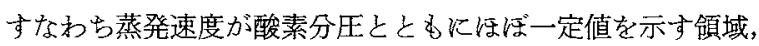
蒸発速度が酸素分圧の増大とともに直線的に大きくなる領域括 上び蒸発が汪とんど進行しない領域(以後順に低酸素分圧領域, 中酸素分圧領域，高酸素分圧領域と呼ぶ)に大別される。この らら高酸素分圧領域では凝縮粒子は忹とんど得られなかったの で，以後の調查対象から除外した。また各酸素分圧における蒸 発速度は，温度が高くなると大きくなった。

低酸素分王領域之中酸素分圧領域の境界となる酸素分圧(以 後境界酸素分圧と呼ぶ)は，温度が高くなるにつれて大きくな った．中酸素分圧領域之高酸素分压領域の境界となる酸素分王 (以後限界酸素分圧と呼ぶ)は，温度が高くなるにつれて大きく なるが, $2173 \mathrm{~K}$ と $2273 \mathrm{~K}$ でのその酸素分生はほぼ等しかっ た. 中酸素分王領域での直楾の傾きは温度が高くなると小さく なる傾向があった。

\section{（2）全ガス流量の影響}

各全ガス流量に和ける蒸発速度と酸素分压の関俰を Fig. 4 に示した．全ガス流量を变えても蒸発速度と酸素分压との関係 は，前述したよらに 3 領域に分けられる，各酸素分化に持い て，全ガス流量が大きくなるにつれて蒸発速度は大きくなった。 $2273 \mathrm{~K}$ の全ガス流量 $25 \times 10^{-5} \mathrm{~m}^{3} \cdot \mathrm{s}^{-1}$ の境界酸素分圧を除い て，境界酸素分圧上限界酸素分圧は各温度に乱いてガス流量に よらずそれぞれ汪ぼ同じであり，また中酸素分圧領域での直線 の傾きは，各温度に执いてガス流量が大きくなると大きくなっ た.

ここで，限界酸素分圧での蒸発速度は最大であるが，この 速度はAr中での蒸発速度の約1.4 4.3倍大きく，むた Langmuir の式から算出される真空中での蒸発速度 ${ }^{(3)}$ よりは1/ $7700 \sim 1 / 2200$ と小さった。

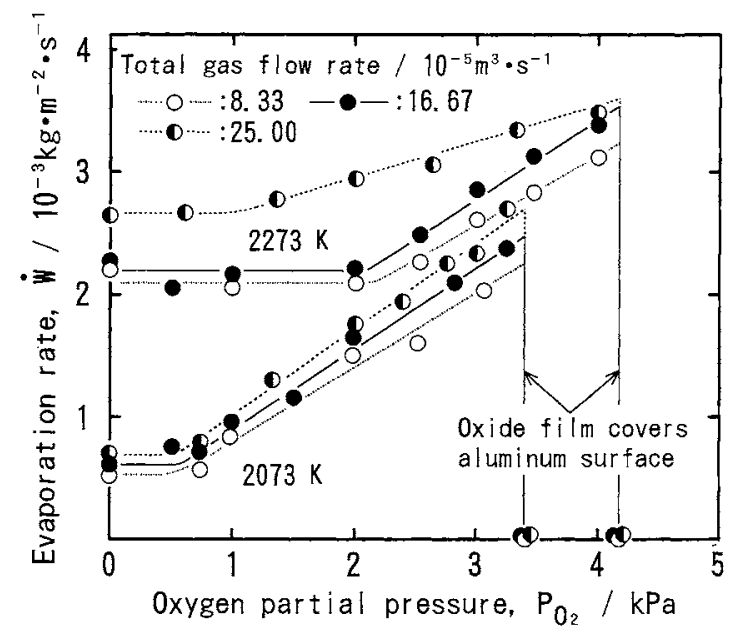

Fig. 4 Effect of $P_{\mathrm{O}_{2}}$ on the evaporation rate at each total gas flow rate.

\section{2. 凝縮粒子}

（1）粒子形状と粒子の同定

凝縮粒子の色は Ar ガスのみの場合火は灰色であり，低酸素 分圧領域では赫色と白色が混在し，酸素分圧が大さくなるにつ れて白色粒子が多くなった。中酸素分圧領域で得られた凝縮粒 子の色は酸素分圧によらず白色で岁った。

粉末 X 線回折の結果をFig. 5 K示した．低酸素分圧領域で は金属 $\mathrm{A} 1$ とルミナのピークが混在しているので，前述した 粒子の色から判断しても，この酸素分圧領域では $\mathrm{Al}+\mathrm{Al}_{2} \mathrm{O}_{3}$ の混合超微粒子が得られていることが分かった。中酸素分王領 域では大部分が $\mathrm{Al}_{2} \mathrm{O}_{3} て ゙ ，$ 金属 $\mathrm{Al}$ の弱いピークも認められ た．検出されたアルミナは酸素分圧と温度によらず準安定相で

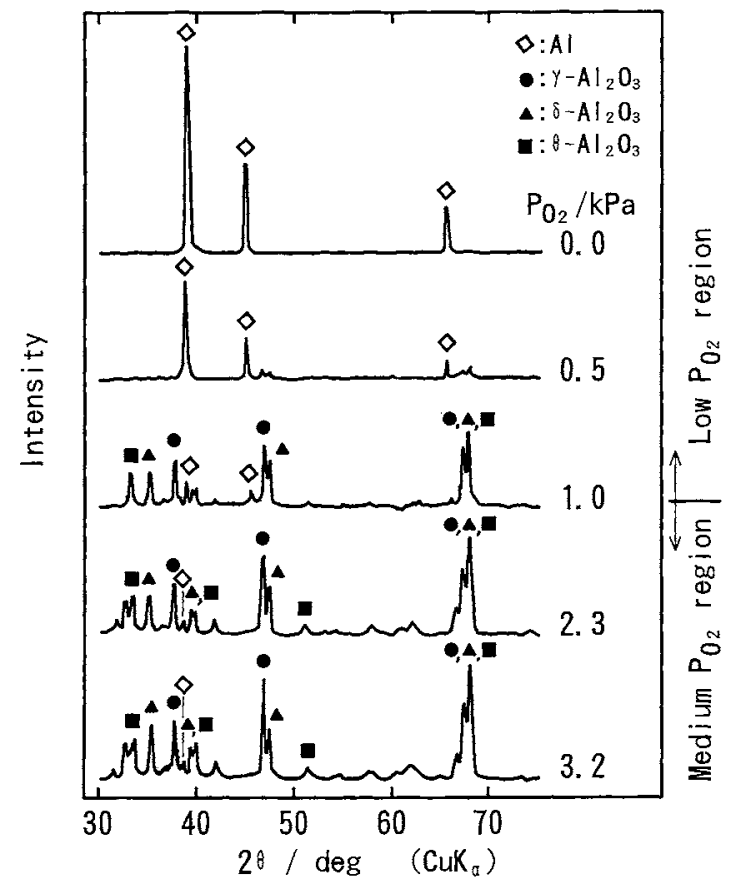

Fig. 5 X-ray diffraction patterns of fine particles obtained at various $P_{\mathrm{O}_{2}}$ (run no. 2 ). 

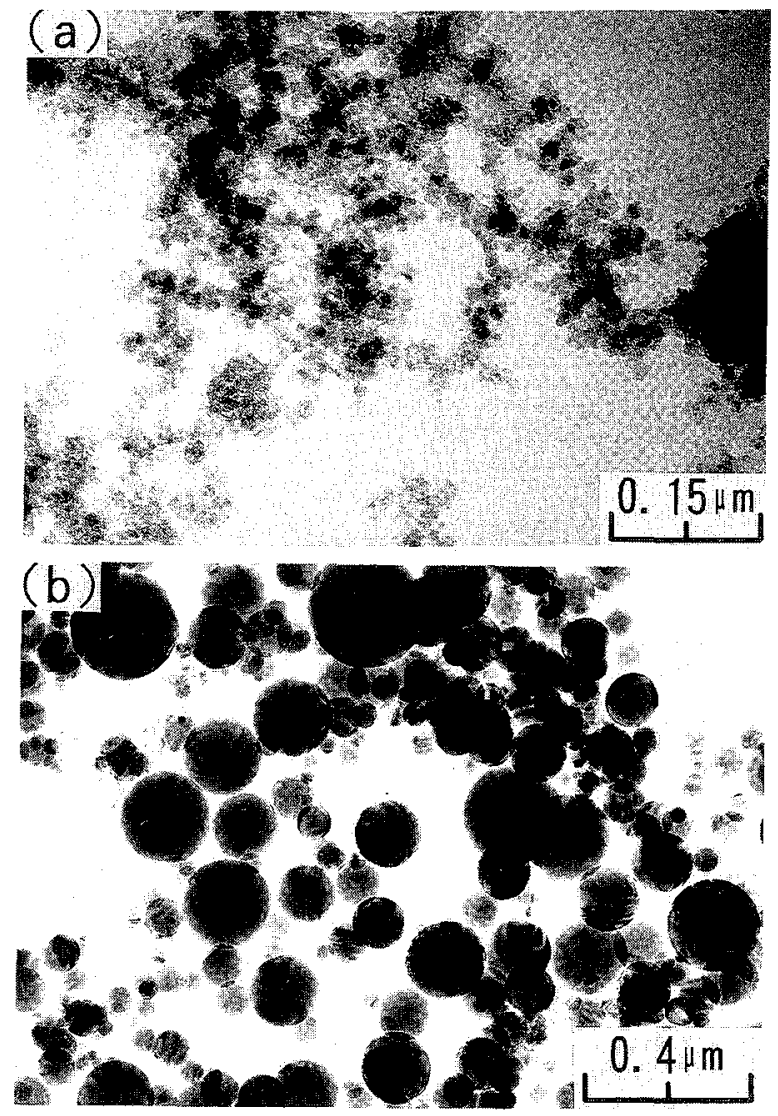

Fig. 6 Transmission electron microphotographs of $y$ $\mathrm{Al}_{2} \mathrm{O}_{3}$ particles obtained at run no. 2; (a) $P_{\mathrm{O}_{2}}=0.51 \mathrm{kPa}$, (b) $P_{\mathrm{O}_{2}}=2.33 \mathrm{kPa}$.

ある広義の $\gamma$ 型 $\left(\gamma, \delta, \theta-\mathrm{Al}_{2} \mathrm{O}_{3}\right)$ であり，安定相である $\alpha$ 型は認 められなかった。

Fig. 6 亿凝縮粒子の形状を例示した．Ar気流中で得られた 椟子は前報で述べたように球形であった。低酸素分圧領域で得 られた粒子は, 数 $\mathrm{nm} の \mathrm{Al}_{2} \mathrm{O}_{3}$ 超微粒子(Fig. 6(a)) と球形の $\mathrm{Al}$ 粒子の混合粒子であった。中酸素分圧領域で得られた $\mathrm{Al}_{2} \mathrm{O}_{3}$ 粒子(Fig. 6(b)) は球形であった. $\mathrm{Al}_{2} \mathrm{O}_{3}$ の粒子形状が球 形で方ることから，この粒子は一旦 $\mathrm{Al}_{2} \mathrm{O}_{3}$ の液相 (m.p. 2323 K)を経ていると考光られる。したがって，液滴粒子が凝固す る際に準安定相の核が出現し, 安定相である $\alpha-\mathrm{Al}_{2} \mathrm{O}_{3}$ に变体す ることなく，準安定相が成長したすのと考兄られる。この粒子 には双晶あるい廭層欠陥が観察された。

\section{(2) 粒子径分布}

Fig. 7 に凝缩粒子の粒子径分布を示した。ただし，低酸素 分压領域での粒子径分布については, Fig. 6(a)k示した数 $\mathrm{nm} の \mathrm{Al}_{2} \mathrm{O}_{3}$ 粒子の計数が困難であったので, 分布の測定は行 わなかった．図の縦軸は確率密度関数に対応するよう火頻度を 分級間隔で除した值である. 粒子径分布は必ずしも一つ山の分 布を示さず, 粒子径の比較的小さいところでは指数分布, 粒径 の比較的大きいとこではひとつ山の分布を示す混合分布を示す 6のもあった，粒子径分布は酸素分圧が大きくなるにつれて粒 子径が小さくから分布範围の狭い方移行する．堿生下に执い て得られた凝縮粒子の粒径分布の多くは幾何標準偏差1.36〜

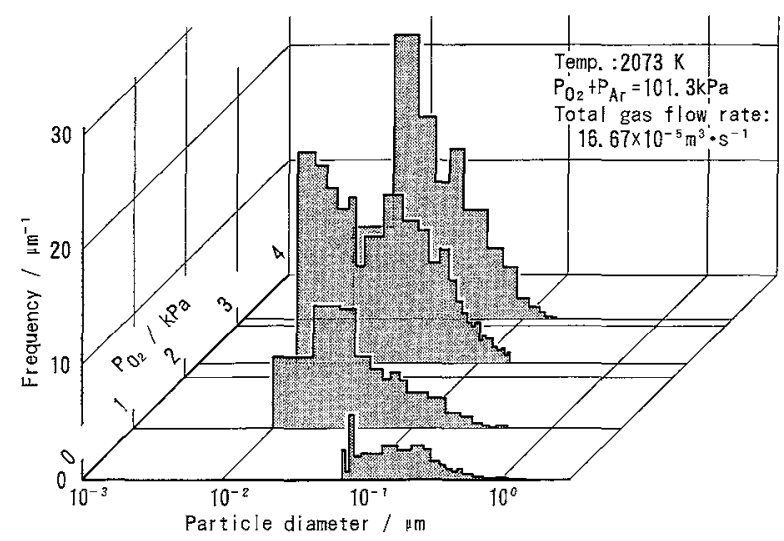

Fig. 7 Particle diameter distributions obtained at various $P_{\mathrm{O}_{2}}$ (run no. 2).

1.600 対数正規分布に従らことが知られている(5)。乙かし本実 験で得られた凝縮粒子の分布は，あ要り対数正規分布には従放 ず，どちらかと言壳ばワイブル分布に近かった．そこで平均粒 子径と分布の広がりを示す分散を累積分布，頻度分布から算出 した。

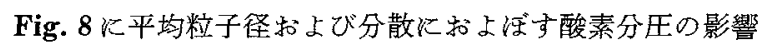
を示した，前述したように低酸素分圧領域での粒子径分有は不 明であるので，平均粒子径と分散は求められないが，酸素分圧 が大きくなるにつれて平均粒子径と分散は小さくなり，限界酸 素分正近くではそれらはは汪一定となった。

Fig. 9 亿各温度に扣忷る限界酸素分圧近傍での平均粒子径 および分散と混合ガス流量の関係をそれぞれ示した，各温度に 执いてガス流量が大きくなると平均粒子径と分散は小さくなる が，ガス流量が $16.67 \times 10^{-5} \mathrm{~m}^{3} \cdot \mathrm{s}^{-1}$ 以上では去机らはガス流 量によらず湮涪一定となった．各がス流量に括いて温度が高く なると平均粒子径拉よび分散す大さくなるが，2073 K と $2173 \mathrm{~K}$ のそれらは汪湾しかった。

\section{N. 考察}

\section{1. 蒸発速度におよばす酸素分圧の影響}

$\mathrm{Al}-\mathrm{O}$ 系の平衡蒸気圧 ${ }^{(6)}$ を本実験条件の酸素分圧とあわせて

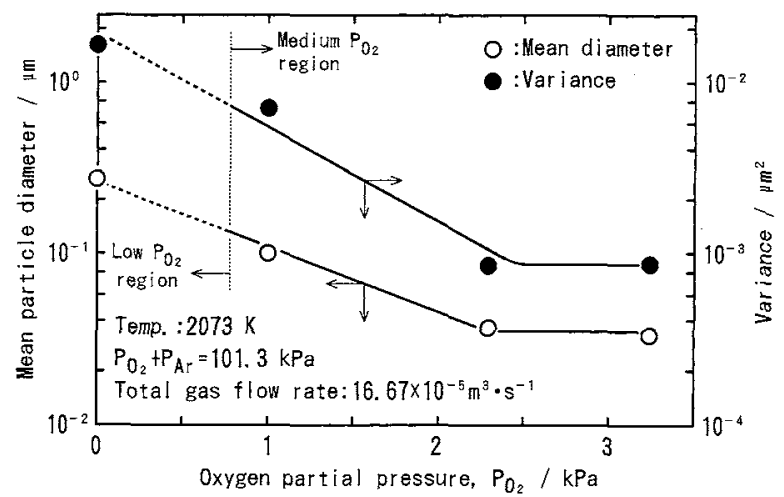

Fig. 8 Effects of $P_{\mathrm{O}_{2}}$ on the mean particle diameter and variance of particle diameter distribution. 


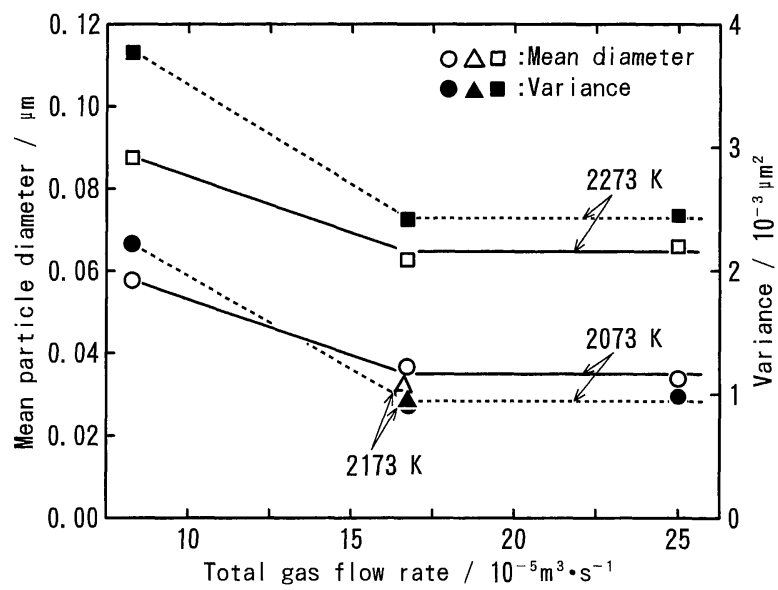

Fig. 9 Effects of total gas flow rate on the mean particle diameter and variance of particle diameter distribution at each temperature. Both mean particle diameter and variance are obtained at $P_{\mathrm{O}_{2}}$ beneath which the oxide film covers the surface of levitated aluminum.

Fig. 10 に例示した. 図に示したアルミナに関するデータは $\alpha$ $\mathrm{Al}_{2} \mathrm{O}_{3}$ のものである. 平衡論的に考察すると, 本実験の酸素分 圧では浮揚 $\mathrm{Al}$ 試料は酸素之

$$
\mathrm{Al}_{(1)}+3 / 4 \mathrm{O}_{2}=1 / 2 \mathrm{Al}_{2} \mathrm{O}_{3(\mathrm{~s})}
$$

で反応し, 浮揚 $\mathrm{Al}$ 試料表面に $\mathrm{Al}_{2} \mathrm{O}_{3}$ 酸化膜が生成することに なる.そのため $\mathrm{Al}$ の蒸発はほとんど期待できない，しかしIII.1 節で述べたように，酸素分圧が限界酸素分圧以下のときは $\mathrm{Al}$ は蒸発し, $\mathrm{Al}_{2} \mathrm{O}_{3}$ 酸化膜が生成するのはそれ以上の酸素分圧に なったときである。したがって, 浮揚 $\mathrm{Al}$ 試料表面の酸素分圧 は気相バルク中のそれよりも著しく小さいと考えられる.

大気圧下での蒸発速度はガス側の物質移動によって律速され る. そこで, Fig. 11 亿模式的に示したように $\mathrm{Al}$ と酸素の対 向拡散を考光，蒸発速度を輸送現象論的に検討する. $\mathrm{Al}$ と酸 素の拡散流束は, 浮揚試料の形状を球とし, 等モル相互拡散, 理想気体，定常状態を仮定すると， $\mathrm{Al}$ 蒸気と $\mathrm{O}_{2}$ の浮揚試料表 面積当たりの拡散流束 $J$ は

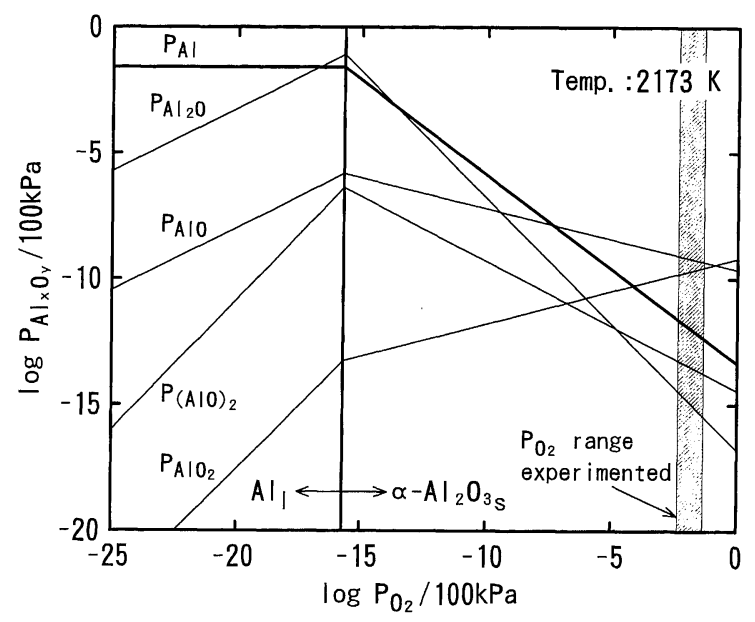

Fig. 10 Relation between equilibrium vapor pressure and $P_{\mathrm{O}_{2}}$.
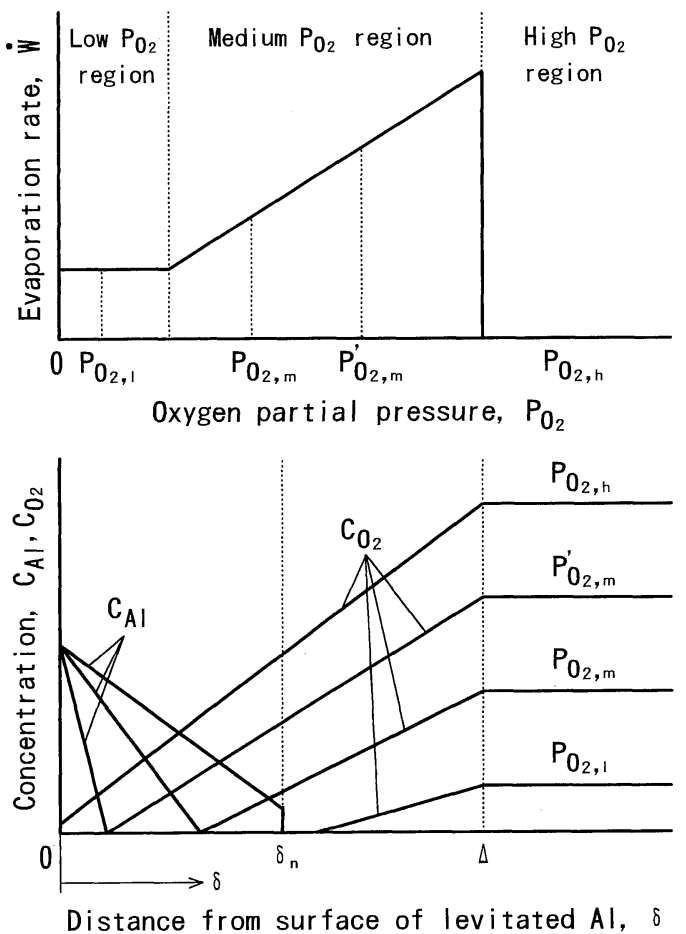

Fig. 11 Schematic diagrams showing the variation in evaporation rate with $P_{\mathrm{O}_{2}}$ (upper part) and counter flux of $\mathrm{Al}$ vapor and $\mathrm{O}_{2}$ (the lower part).

$$
\begin{aligned}
& J_{\mathrm{Al}}=\frac{D_{\mathrm{Al}}}{r_{\mathrm{s}}^{2}} \frac{C_{\mathrm{Al}, \mathrm{s}}-C_{\mathrm{Al}}}{1 / r_{\mathrm{s}}-1 /\left(r_{\mathrm{s}}+\delta\right)} \\
& J_{\mathrm{O}_{2}}=-\frac{D_{\mathrm{O}_{2}}}{r_{\mathrm{s}}^{2}} \frac{C_{\mathrm{O}_{2}}-C_{\mathrm{O}_{2, \mathrm{~b}}}}{1 /\left(r_{\mathrm{s}}+\delta\right)-1 /\left(r_{\mathrm{s}}+\Delta\right)}
\end{aligned}
$$

と表せる．ここで， $J, D, C$ は添学字で示したものの流束 $[\mathrm{mol}$. $\left.\mathrm{m}^{-2} \cdot \mathrm{s}^{-1}\right]$, 相互拡散係数 $\left[\mathrm{m}^{2} \cdot \mathrm{s}^{-1}\right]$, 濃度 $\left[\mathrm{mol} \cdot \mathrm{m}^{-3}\right], r$ は浮揚 試料中心からの距離 $[\mathrm{m}], \delta$ は浮揚試料表面からの距離 $[\mathrm{m}], \Delta$ は境界層厚さ $[\mathrm{m}]$ であり, 添兄字 $\mathrm{s}$ と b は浮揚 $\mathrm{Al}$ 試料表面と 気体バルク中での值を示す．また $C$ は

$$
C=P / R T
$$

で表せる．ここで $P$ は各成分の分圧(蒸気圧) $[\mathrm{Pa}], R$ は気体定 数 $\left[\mathrm{J} \cdot \mathrm{K}^{-1} \cdot \mathrm{mol}^{-1}\right], T$ は温度 $[\mathrm{K}]$ である.

以下に各酸素分圧領域に扣潦発速度と酸素分圧との関係 について述べる.

\section{(1) 低酸素分圧領域}

前報で述べたように，低温度の不活性ガス気流中では $\mathrm{Al}$ 蒸 気はガス側境界層 $\Delta$ 内で均質核生成に基づいて凝縮する。こ の時の蒸発速度 $\dot{W}$ は式 $(2)$ より,

$$
\dot{W}=M_{\mathrm{Al}} D_{\mathrm{Al}}\left(1+\frac{\delta_{\mathrm{n}}}{r_{\mathrm{s}}}\right) \frac{C_{\mathrm{Al}, \mathrm{s}}-C_{\mathrm{Al}, \mathrm{n}}}{\delta_{\mathrm{n}}}
$$

で表せる(2).ここで, $\dot{W}$ 蒸発速度 $\left[\mathrm{kg} \cdot \mathrm{m}^{-2} \cdot \mathrm{s}^{-1}\right], M_{\mathrm{Al}}$ は $\mathrm{Al}$ の 原子量 $\left[\mathrm{kg} \cdot \mathrm{mol}^{-1}\right]$, 下つきの添え字の $\mathrm{n}$ は凝縮位置での值を 示す.

低酸素分圧領域に括いては，モデル的には Fig. 11 中の $P_{\mathrm{O}_{2, l}}$ で示した状態にあると考兄られる。すなわちバルク中の酸素分 圧 $P_{\mathrm{O}_{2}}$ が小さいので酸素の流束 $J_{\mathrm{O}_{2}}$ 子小さく, 境界層内を拡散 する注とんどすべての酸素は $\mathrm{Al}$ 蒸気が凝縮した後の液滴粒子 
と式 (1) で反応する.よって酸素は $\mathrm{Ar}$ 気流中で $\mathrm{Al}$ 蒸気が凝 縮する位置 $\delta_{\mathrm{n}}$ よりも浮揚試料側に拡散しないので, $C_{\mathrm{Al}, \mathrm{n}}, \delta_{\mathrm{n}}$ 扣よび $D_{\mathrm{Al}}$ は酸素分圧によらず一定となり, 蒸発速度も酸素分 圧によらず一定となる.

\section{(2) 中酸素分圧領域}

中酸素分圧領域に执いては蒸発速度は酸素分圧の増大ととも に大きくなるので，モデル的には Fig. 11 の $P_{\mathrm{O}_{2, \mathrm{~m}}}$ の状態が考 えられる.すなわら酸素分圧が大きくなるにつれて酸素の流束 が大きくなり，酸素は $\mathrm{Ar}$ 気流中で $\mathrm{Al}$ 蒸気が凝縮する位置 $\delta_{\mathrm{n}}$ よりも試料側に拡散する. $\mathrm{Al}$ 蒸気の拡散種に単原子を仮定す ると,

$$
\mathrm{Al}_{(\mathrm{g})}+3 / 4 \mathrm{O}_{2}=1 / 2 \mathrm{Al}_{2} \mathrm{O}_{3(1)}
$$

の気相反応で $\mathrm{Al}_{2} \mathrm{O}_{3}$ は生成する.したがって浮揚試料表面か ら反応が生じる位置までの距離 $\delta$ が, $\mathrm{A} 1$ 蒸気が拡散する境界 層厚さとなる.中酸素分圧領域で得られる粒子は汪とんど $\mathrm{Al}_{2} \mathrm{O}_{3}$ であるので, $\mathrm{Al}$ 蒸気の拡散流束と酸素の流束との関係 は

となる.

$$
J_{\mathrm{Al}}=-4 / 3 \cdot J_{\mathrm{O}_{2}}
$$

$\mathrm{Al}_{2} \mathrm{O}_{3}$ の析出が過飽和を必要とする場合, 総括の過飽和比 $\alpha$ は式 ( 6 )の平衡定数を $K_{(6)}$ とすると

$$
\alpha=K_{(6)}\left(P_{\mathrm{Al}, \delta} \cdot P_{\mathrm{O}_{2}, \delta}^{3 / 4}\right)
$$

で表される.ここで下付きの $\delta$ は反応位置を示す。 また式 $(8)$ は反応位置での $P_{\mathrm{Al}}$ と $P_{\mathrm{O}_{2}}$ の関係をも示している.

本実験では反応が生じる位置, 分圧(蒸気圧)拈よび過飽和比 を特定することはできない.そこで Turkdogan ら (3) と同様に, $P_{\mathrm{O}_{2, \delta}}$ は $P_{\mathrm{O}_{2, \mathrm{~b}}}$ に比べて十分に小さいと仮定して, 式(7)を用い て $\mathrm{Al}$ の蒸発速度を $\mathrm{O}_{2}$ の流束から検討する。ここで, $r_{\mathrm{s}}$ は約 $7.4 \mathrm{~mm}$ であり, 後述するようにして求めた境界層厚さ $\Delta$ は約 $3.0 \sim 5.2 \mathrm{~mm}$ であった。 また $\delta_{\mathrm{n}}$ は $0.31 \sim 0.54 \mathrm{~mm}$ であり(2), 反応が生じる位置 $\delta$ は $\delta \leqq \delta_{\mathrm{n}}$ であるので, 蒸発速度 $\dot{W}$ は式 $(3)$ と式( 7 ) より近似的に

$$
\dot{W} \fallingdotseq X_{\mathrm{cal}} P_{\mathrm{O}_{2}, \mathrm{~b}}
$$

と表される.ここで $X_{\mathrm{cal}}$ は

$$
X_{\mathrm{cal}}=\frac{4 M_{\mathrm{Al}} D_{\mathrm{O}_{2}}}{3 R T_{\mathrm{b}}(\Delta-\delta)}\left(1+\frac{\Delta+\delta}{r_{\mathrm{s}}}\right)
$$

である.

Fig. 11 に示したように, 酸素分圧が増大する $\left(P_{\mathrm{O}_{2, \mathrm{~m}}} \rightarrow P_{\mathrm{O}_{2, \mathrm{~m}}}^{\prime}\right)$ と反応位置までの距離 $\delta$ は小さくなると考学られる．実験で 得られた蒸発速度は酸素分圧とともに直線的に増大寸るので, $X_{\text {cal }}$ は酸素分圧によらず一定になるはずである。そこで，まず 試料周辺の温度分布 (Fig. 12) を求め, 相互拡散係数 $D_{\mathrm{O}_{2}}$ を $\delta$ から $\Delta$ の幾何平均温度 $(T \cdot 293)^{1 / 2}$ で算出し, 式(10)より $X_{\text {cal }}$ を求めた. 温度分布と相互拡散係数の算出方法は扮和よそ前 報(2) に記した通りである，ただし，温度分布の算出に必要なレ イノルズ数とプラントル数などの值には, 混合ガス中の酸素濃 度は約 $4.3 \mathrm{~mol} \%$ 以下であるので, Arでの值を用いた。 また 反応熱は無視し， $\Delta$ には温度境界層厚さを用いた。これについ ては後述する.

Fig. 12 に $X_{\text {cal }}$ と $\delta$ の関係を示した. $X_{\text {cal }}$ は $\delta$ の増大に伴い ゆるやかに増大するが， $0 \leqq \delta \leqq \delta_{\mathrm{n}}$ での $X_{\text {cal }}$ の増加率は約 $3 \%$ であるので，この区間では $X_{\text {cal }}$ は一定值と見なしてょい。し
たがって, 酸素分圧が増大すると $\delta$ は減少するので, 式(2) より $\mathrm{Al}$ の拡散流束は大きくなり, $\mathrm{Al}$ の蒸発速度 $\left(\dot{W}=M_{\mathrm{Al}} J_{\mathrm{Al}}\right)$

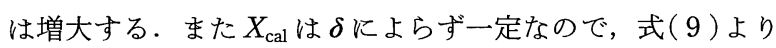
蒸発速度は酸素分圧とともに直線的に增大寸ることになる。

Fig. 13 亿 Fig. 3 と Fig. 4 亿示した中酸素分圧領域での直線 の傾き $X_{\mathrm{obs}}$ と $X_{\mathrm{cal}}$ とを比較して示した. Run no. 7 を除いて, 両者の值は比較的によく一致している. 一定温度でガス流量が 大きくなると(Run nos. 1〜3 と nos. 5〜7), Run no. 7 を除い て $X_{\text {cal }}$ と $X_{\mathrm{obs}}$ はともに大きくなり，両者の傾向は一致してい る. 一定ガス流量で温度が大きくなると(Run nos. 1, 5, nos. 2, 4, 6 㧊よび nos. 3, 7)， $X_{\text {cal }}$ は大きくなるが， $X_{\text {obs }}$ は小さく なり, 両者の傾向は一致しない.ガス流量の $X_{\mathrm{obs}}$ に扣よぼす 影響については，ガス流量が増大すると $\Delta$ が小さくなるので $X_{\mathrm{obs}}$ は大きくなると本モデルからは説明できる，乙かし，温 度の影響については，本モデルからは説明できない。これは $P_{\mathrm{O}_{2}}^{\prime}$ は $P_{\mathrm{O}_{2}}$ に比べて十分に小さいと仮定していることに起因す ると考えられる。また，ここでは $X_{\text {cal }}$ を算出する際の $\Delta$ に温 度境界層厚さを用いたが，本来は濃度境界層厚さを用いなけれ ばならない，II節で述べたことからも分かるよらに，浮揚試料

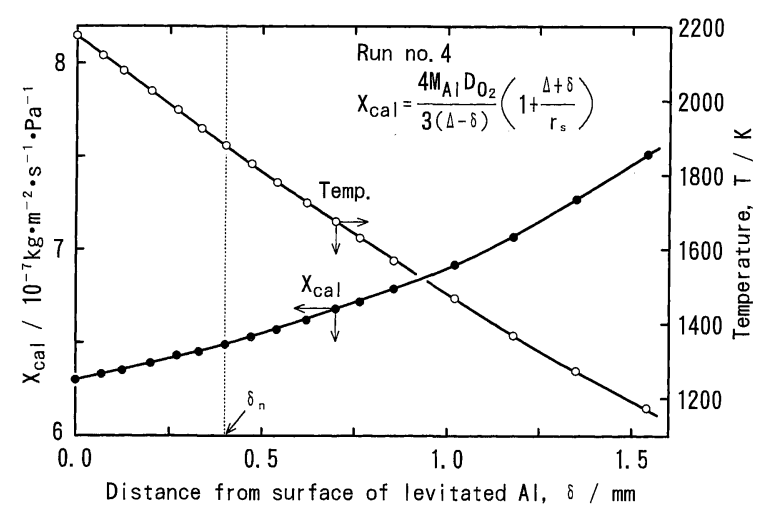

Fig. 12 Distributions of temperature and $X_{\text {cal }}$ at surrounding of levitated aluminum.

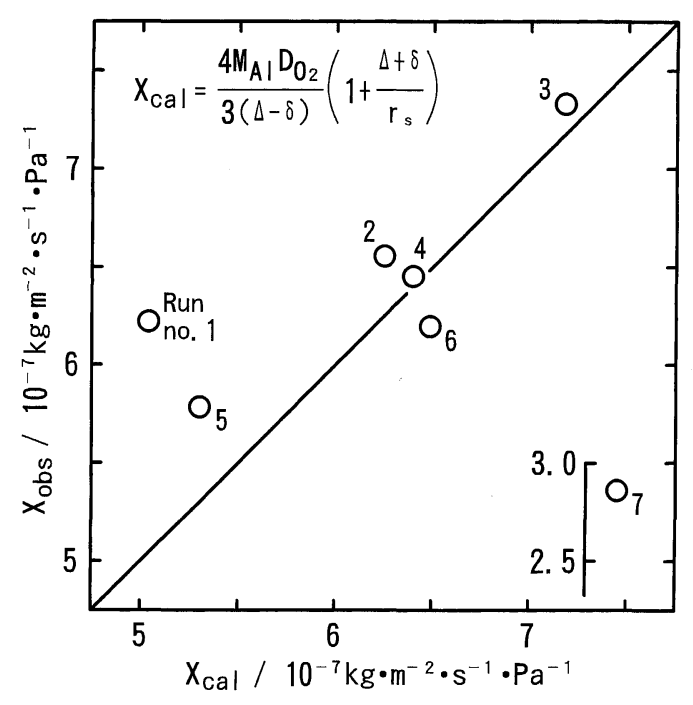

Fig. 13 Comparison between $X_{\text {obs }}$ and $X_{\text {cal }} ; X_{\text {obs }}$ are the gradients of lines existing in the medium $P_{\mathrm{O}_{2}}$ range. 
は誘導電流と反応熱によって加熱され，実験温度に保持されて いる. それゆえ，試料周辺の温度はFig. 12 飞示したよらな単

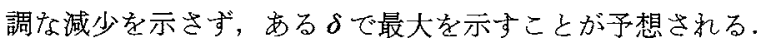
$X_{\text {cal }}$ は $X_{\text {obs }}$ とほぽ一致していることから，実際の濃度境界層 厚さは反応㙓を無視して得られた温度境界層厚さ见近いものと 考光られる、今後，反応が生じる位置，その位置での分圧(蒸 気厈)，過飽和比ならびに反応熱を考慮したより詳細なモデル による検討が必要である. Run no. 7 の $X_{\text {obs }}$ と $X_{\text {cat }}$ が著しく 異なる原因は不明であるが，Alの蒸発速度が最大であるので 反応熱総量も大きくなり，生成した $\mathrm{Al}_{2} \mathrm{O}_{3}$ が再蒸発すること 6一因之して挙げられる。

\section{(3) 高酸素分圧領域}

この領域では浮揚 $\mathrm{Al}$ 表面に酸化膜が生成するので，モデル 的にはFig. $11 の P_{\mathrm{O}_{2, \mathrm{~h}}}$ の状態が考えられる.すなわち酸素分 圧が大きいので酸素の推散流束 $J_{O_{2}}$ は, Al の蒸気と式(5)で 反応するのに要する酸素流束以上に大きくなる。したがって酸 素は浮揚 $\mathrm{Al}$ 表面江拡散し, その表面で式 (1)により $\mathrm{Al}_{2} \mathrm{O}_{3}$ の 酸化膜を生成する.ただし, 本実験温度範囲では Fig. 10 亿示 したように $\mathrm{Al}_{2} \mathrm{O}$ の蒸気圧が大きいので, 浮揚試料表面に生成 したあるいは気相反応で生成した後に浮揚試料表面に付着した $\mathrm{Al}_{2} \mathrm{O}_{3}$ は，試料表面での酸素分圧が十分に小さければ，

$$
4 \mathrm{Al}_{(1)}+\mathrm{Al}_{2} \mathrm{O}_{3(\mathrm{~s})}=3 \mathrm{Al}_{2} \mathrm{O}_{(\mathrm{g})}
$$

の反応で除去される．したがって， $\mathrm{Al}_{2} \mathrm{O}_{3}$ 酸化膜が生成する条 件は，酸素の拡散流束が $\mathrm{Al}_{2} \mathrm{O}$ による酸素除去流束を越えたと さになる。

ここで, 限界酸素分圧での蒸気速度は真空中での蒸発速度に 等しいことが報告されている(3)。乙かし，III.1.(2)節で述べた よ5に，本実験では限界酸素分圧の蒸発速度は真空中でのそれ よりも著しく小さい。これは, 実験温度よりる低い温度で所定 流量の酸素を導入していることに起因する。

\section{2. 颣縮粒子}

\section{（1）低酸素分圧領域}

低酸素分圧領域では酸素は $\mathrm{Al}$ 蒸気凝縮後の液滴粒子と反応 する。酸素の流束が式（7)から得られる $\mathrm{Al}_{2} \mathrm{O}_{3}$ 生成に必要な 酸素の昖散流束よりも小さいので㠜縮粒子は $\mathrm{Al}$ 々 $\mathrm{Al}_{2} \mathrm{O}_{3}$ が得 られ，バルク中の酸素分圧(酸素の流束)が大さくなるにつれ て， $\mathrm{Al}_{2} \mathrm{O}_{3}$ の生成量む大きくなるすのと考元られる。

\section{(2) 中酸素分圧領域}

この酸素分压領域では, 式(7)の関係が成立するので, $\mathrm{Al}_{2} \mathrm{O}_{3}$ 粒子のみが得られる. $\mathrm{Al}_{2} \mathrm{O}_{3}$ の平均粒子径は, 全般的な 傾向として, 酸素分圧と全がス流量が大きくなると減少し, 温 度が高くなると增大寸る. $\mathrm{Al}_{2} \mathrm{O}_{3}$ の粒子は液相を経ていると考 えられるので, 前報と同様に $\mathrm{Al}_{2} \mathrm{O}_{3}$ の融点以上の温度範囲が 粒子成長に関与すると思われる. しかし, 浮揚試料周辺の温度 分布や濃度分布, 屯大核生成に関与する過飽和比炕ついてる, さらに核生成が必要か否かについてる不明であるので, 粒子徍 に扣よぼす酸素分圧, 温度扣よび全ガス流量の影響を棗密には 論じられない。

\section{3. 他の蒸発疑縮法で得られた $\gamma-\mathrm{Al}_{2} \mathrm{O}_{3}$ 粒子との比較}

殷島 (7) は低圧下での $\mathrm{Ar}+\mathrm{O}_{2}$ 混合ガス気流中で Al 電極を用
いたアーク放電法を用いて $5 \sim 70 \mathrm{~nm} の \gamma-\mathrm{Al}_{2} \mathrm{O}_{3}$ を合成してい る. 一方平山 ${ }^{(8)}$ はバーナー法で $10 \sim 250 \mathrm{~nm}$ の $\gamma-\mathrm{Al}_{2} \mathrm{O}_{3}$ を大気 圧下で合成した，本実験では実験条件により得られる $\boldsymbol{\gamma}-\mathrm{Al}_{2} \mathrm{O}_{3}$ の粒径が異なるが，平均径が最小となる時の粒径分布範囲は 5 170 nmであった．各方法で得られる粒子の大きさを比較 すると，大気圧下での製造方法であるバーナー法と本方法で得 られる粒子の大きさは減圧下でのアーク放電法よりも大きい が，同じ大気压下での製造方法であるバーナー法よりる本実験 方法の方が小さい粒子ができるようである。

\section{V. 結言}

浮揚溶解した $\mathrm{Al}$ を $\mathrm{Ar}+\mathrm{O}_{2}$ 混合ガス中で蒸発させる実験を 行った。蒸発速度の酸素分王低存性は低酸素分王領域，中酸素 分压領域そして高酸素分王領域の 3 領域で異なっていた。各 酸素分厈領域における，Al の蒸発速度を酸素の拡散流束から 検討した. 各酸素分圧領域での蒸発速度と凝縮粒子について以 下に李とめて記した。

(1) 低酸素分圧領域：酸素は $\mathrm{Al}$ 蒸気凝縮後の液滴粒子と反 応するので，蒸発速度は酸素分圧によらず Ar 中での速度に等 しかった。凝縮粒子は球形の金属 $\mathrm{Al}$ 粒子と広義の $\gamma-\mathrm{Al}_{2} \mathrm{O}_{3}$ 粉 末の混合微粒子が得られた。

（2）中酸素分圧領域：酸素は $\mathrm{Al}$ 蒸気と反応する．酸素分圧 の増大几伴い $\mathrm{Al}$ 蒸気の抎散に関する境界層厚さが減少するの で，蒸発速度は直線的に堌大した。凝縮粒子は球形の広義の $\gamma-\mathrm{Al}_{2} \mathrm{O}_{3}$ 超微粒子であった．全般的に見て，凝縮粒子の平均径 は酸素分圧支るいは全ガス流量の増大に伴い減少し，温度が高 くなると璔大した。

(3) 高酸素分圧領域：酸素は浮揚 $\mathrm{Al}$ 試料と反応し， $\mathrm{Al}$ 表面 に $\mathrm{Al}_{2} \mathrm{O}_{3}$ 酸化皮膜が生成した。したがって蒸発は后とんど進 行せず，凝縮粒子す得られなかった。

本実験を遂行するにあたり，TEM 拈よび SEM 観察に協力 していただいた豊橋技術科学大学 村田純教工学博士ならびた 白井宏始文部技官に感謝の意を表します。

\section{文献}

（1）例亲ば，社日本粉体工業技術協会編：超微粒子応用技 術, 日刊工業新聞社，(1986), 23.

（2）横山誠二, 小久保貞男, 斎藤已由, 伊藤公允, 川上 正博 : 日本金属学会誌, 57 (1993), 54 .

(3) E. T. Turkdogan, P. Grieveson and L. S. Darken: J. Phys. Chem., 67(1963), 1647.

(4) P. A. Distin and S. G. Whiteway: Can. Metall. Quart., $9(1970), 419$.

（5）奥山喜久夫, 吉沢昭宣 : エアロゾル研究，3(1988), 6.

(6) M. W. Chase, Jr., C. A. Davies, J. R. Downey, Jr., D. J. Frurip, R. A. McDonald and A. N. Syverud: J. Phys. Chem. Ref. Data Vol. 14, (1985), No. 1 JANAF Thermochemical Tables Third Edition Part 1, Amer. Chem. Soc. and Amer. Inst. Phys., (1985), 65, 134, 137, 152, $154,156$.

（7）飯島澄男(林 主税, 上田良二, 田崎 明編）: 超徽粒子創造科学技術, 三田出版会, (1988), 53 .

（8）平山 司：弿業協会誌，95 (1987)，253. 